\title{
Efek Variasi Waktu dan Jumlah Lilitan pada Sistem Filter Elektromagnetik Terhadap Penurunan Kadar $\mathrm{Pb}, \mathrm{Zn}$ dan Co
} (Effects of Time Variation and Number of Turns in Electromagnetic Filter Systems on Decreasing Levels of $\mathrm{Pb}, \mathrm{Zn}$ and $\mathrm{Co}$ )

\author{
R. Eso ${ }^{1 *}$, M. A. A. Undu ${ }^{1}, \operatorname{Sumarno}^{1}$ dan M. Anas ${ }^{1}$ \\ 1) Jurusan Pendidikan Fisika Universitas Halu Oleo
}

Info

\section{Article history:}

Received: 03 Desember 2020

Accepted: 30 Desember 2020

Published: 31 Desember 2020

\begin{abstract}
Abstrak.
Telah dibuat filter elektromagnetik yang berisi 350 gram pasir besi yang diambil dari Pantai Laeya Kabupaten Buton Selatan sebagai filler. Filter elektromagnetik menggunakan pipa PVC berdiameter 1 inci dan menggunakan rangkaian listrik dengan tegangan 16 Volt. Filter ini digunakan untuk menyerap logam berat pada sampel air Teluk Kendari dengan memvariasikan waktu penyaringan 5, 10, 15, 20 hingga 25 menit dan jumlah lilitan kawat 1300, 1600 dan 2000. Kadar logam yang diukur dengan metode Spektrofotometer Serapan Atom (SSA) menunjukkan penurunan optimum kadar logam berat pada 25 menit penyaringan berturut-turut $0,0333 \mathrm{mg} / \mathrm{l}$, $0,0785 \mathrm{mg} / \mathrm{l}$, dan $0,0181 \mathrm{mg} / \mathrm{l}$ untuk $\mathrm{Pb}$, Zn, dan Co dengan penyerapan maksimum berturut-turut $96,02 \%, 82,86 \%$ dan 75,57\% untuk $\mathrm{Pb}, \mathrm{Zn}$ dan Co. Variasi jumlah lilitan kawat memperoleh hasil optimum pada 2000 lilitan yaitu berturut-turut $0,0026 \mathrm{mg} / \mathrm{l}, 0,0131 \mathrm{mg} / \mathrm{l}$, dan $0,0063 \mathrm{mg} / \mathrm{l}$ untuk $\mathrm{Pb}, \mathrm{Zn}$, dan $\mathrm{Co}$. Hal ini menunjukan filter elektromagnetik mampu menurunkan kadar logam $\mathrm{Pb}, \mathrm{Zn}$ dan Co dengan serapan hampir mencapai $100 \%$.
\end{abstract}

Abstract.

An electromagnetic filter has been made containing 350 grams of iron sand taken from Laeya Beach, South Buton Regency as a filler. The electromagnetic filter uses 1 inch diameter PVC pipe and uses an electric circuit with a voltage of 16 Volt. This filter is used to absorb heavy metals in Kendari Bay water samples by varying the filtering time of 5, 10, 15, 20 to 25 minutes and the number of turns of wire 1300, 1600 and 2000.The metal content measured by the Atomic Absorption Spectrophotometer (AAS) method shows a decrease. The optimum levels of heavy metals at 25 minutes of filtering were $0.0333 \mathrm{mg} / l, 0.0785 \mathrm{mg} / \mathrm{l}$, and $0.0181 \mathrm{mg} / \mathrm{l}$ respectively for $\mathrm{Pb}, \mathrm{Zn}$, and Co with a maximum absorption of $96.02 \%$, respectively. $82.86 \%$ and $75.57 \%$ for $\mathrm{Pb}, \mathrm{Zn}$ and $\mathrm{Co}$. The variation in the number of turns of wire obtained the optimum results at 2000 turns, namely $0.0026 \mathrm{mg} / \mathrm{l}, 0.0131 \mathrm{mg} / \mathrm{l}$, and $0.0063 \mathrm{mg} / \mathrm{l}$ for $\mathrm{Pb}, \mathrm{Zn}$, and Co., respectively. This shows that the electromagnetic filter can reduce the levels of $\mathrm{Pb}, \mathrm{Zn}$ and Co metals with absorption almost $100 \%$
Keywords:

Electromagnetic Filter

Heavy Metal

Iron Sand

Spectrophotometer

Atomic Absorption

\section{PENDAHULUAN}

Seiring berkembangnya teknologi, sektor industri perikanan, pertanian dan kegiatan transportasi laut mendapatkan dampak negatif yang diantaranya adalah peningkatan volume limbah logam berat dari berbagai kawasan di wilayah pesisir, yang bila melampaui keseimbangan air laut akan mengakibatkan sistem perairan tercemar [1]. Logam berat merupakan polutan yang berbahaya bagi kesehatan manusia karena tidak dapat terurai secara alami namun mengendap sebagai residu dalam tubuh yang disebabkan oleh proses bioakumulasi yang berarti akan meningkatkan konsentrasi unsur kimia dalam tubuh makhluk hidup [2]. Hal demikian menyebabkan terhambatnya pertumbuhan, menimbulkan cacat fisik, menurunkan kecerdasan, serta melemahkan sistem syaraf. Logam berat yang mencemari lingkungan adalah timbal $(\mathrm{Pb})$, seng $(\mathrm{Zn})$, kobalt $(\mathrm{Co})$, tembaga $(\mathrm{Cu})$, dan natrium $(\mathrm{Na})$ [3]. Akumulasi logam $\mathrm{Pb}$ dan $\mathrm{Zn}$ di perairan Teluk Kendari telah melampaui 
baku mutu yang ditetapkan yaitu $0,03 \mathrm{mg} / \mathrm{l}$ dan $0,05 \mathrm{mg} / \mathrm{l}$ [4]. Demikian juga logam Co yang terakumulasi di teluk kendari mencapai hingga 0,127 mg/l [5]. Demikian dapat disimpulkan bahwa perairan Teluk Kendari tidak ramah untuk kesehatan masyarakat terutama bagi para nelayan Kota Kendari.

Upaya menurunkan kelarutan logam berat di teluk Kendari telah dilakukan melalui cara fisika, kimia maupun biologi, diantaranya menggunakan arang aktif yang diaktivasi secara fisika [5], menggunakan mikroorganisme atau mikrobia yang dalam istilah biologi dikenal dengan bioakumulasi, bioremediasi atau bioremoval untuk penanganan logam berat [6] dan menggunakan reaksi yang terjadi pada kulit kerang sehingga menghasilkan kalsium karbonat ( $\mathrm{CaCo} 3)$ yang kalsiumnya dapat mengikat logam. Namun, metode penurunan kadar logam diperairan kurang efektif sehingga pada penelitian ini akan menggunakan metode sistem penyaring elektromagnetik yang memanfaatkan prinsip medan magnet yang ditimbulkan oleh adanya arus listrik yang dialirkan kesebuah solenoida ideal dengan menggunakan pasir besi sebagai media penyaring (adsorpsi) yang merupakan bahan yang mudah termagnetisasi sehingga dapat menarik logam-logam yang masuk ke dalam sistem penyaring sekaligus mengurangi warna dan bau pada perairan yang telah tercemar tersebut. Kandungan mineral yang dominan dalam pasir besi adalah $\mathrm{Fe} 3 \mathrm{O} 4[7,8]$, dan dewasa ini berkembang produksi mineral magnetik ini berskala nanopartikel [9] dan untuk aplikasi material feroelektrik [10].

Mengingat pentingnya upaya penurunan kadar logam berat $\mathrm{Pb}, \mathrm{Zn}$ dan Co di Teluk Kendari yang sudah melampaui kadar maksimun yang diperbolehkan oleh pemerintah $(\mathrm{Pb}$ sebesar 0,03 mg/L, Zn 0,05 mg/L, dan Co 0,2 mg/L) [11], maka penelitian ini sangat penting untuk dilakukan yakni dengan memvariasikan waktu penyaringan dan jumlah lilitan pada filter elektromagnetik untuk mendapatkan penurunan kadar logam berat yang optimum.

\section{BAHAN DAN METODE}

Pembuatan sistem filter elektromagnetik menggunakan material pasir besi yang di ambil dari Kecamatan Laeya Kabupaten Buton Selatan dengan terlebih dahulu mencuci sampel pasir besi menggunakan aquades dan dikeringkan dibawah sinar matahari. Selanjutnya, memisahkan antara material magnetik dan non magnetik pada sampel menggunakan magnet yang kemudian dihaluskan menggunakan mortar yang kemudian ditimbang menggunakan neraca digital sebanyak 350 gram. Tahapan selanjutnya yaitu membuat rangkaian sistem penyaring dibuat dari pipa PVC (Polyvinil Chloride) dengan ukuran 1 inci sepanjang $50 \mathrm{~cm}$ dan kawat tembaga yang digunakan berdiameter $0,1 \mathrm{~mm}$ dengan jumlah lilitan 1300, 1600 dan 2000 lilitan. Sampel pasir besi dimasukan kedalam solenoida yang telah dibuat dan dialirkan sampel air dari teluk Kendari yang mengandung logam berat untuk menurunkan kadar logam yang terdapat didalamnya. Alat sistem penyaring elektromagnetik ini selanjutnya diuji melalui pengukuran besar medan magnet solenoida, pengecekan peralatan dan pengaturan debit air. Penentuan kadar logam $\mathrm{Pb}, \mathrm{Zn}$ dan $\mathrm{Co}$ menggunakan metode Spektofotometer Serapan Atom (SSA).

\section{HASIL DAN PEMBAHASAN}

3.1. Efek variasi vaktu terhadap penurunan $\mathrm{Pb}, \mathrm{Zn}$ dan $\mathrm{Co}$ Tahap awal penelitian ini menggunakan 1300 lilitan pada pipa filter elektromagnetik yang berisi pasir besi dengan memvariasikan waktu penyaringan. Hasil Uji Penurunan kadar logam $\mathrm{Pb}, \mathrm{Zn}$ dan $\mathrm{Co}$ berdasarkan waktu penyaringan dengan metode analisis SSA dapat dilihat pada Tabel 1.

\subsection{Efek variasi jumlah lilitian kawat terhadap penurunan Pb, Zn dan Co}

Tahapan selanjutnya pengujian terhadap optimasi penurunan kadar logam $\mathrm{Pb}, \mathrm{Zn}$ dan $\mathrm{Co}$ dengan memvariasikan jumlah lilitan kawat pada filter elektromagnetik sementara itu waktu penyiraman dipilih 15 menit. Hasil pengukuran kadar logam dengan metode analisis SSA dilihat pada Tabel 2.

\subsection{Efektivitas penyerapan logam $\mathrm{Pb}, \mathrm{Zn}$ dan Co dengan menggunakan sistem filter elektromagnetik}

Hasil analisis variasi waktu terhadap efektivitas penyerapan logam berat $\mathrm{Pb}, \mathrm{Zn}$ dan $\mathrm{Co}$ menggunakan sistem filter elektromagnetik dapat dilihat pada Gambar 1.

$\underline{\text { Tabel 1. Hasil Uji Penurunan Logam } \mathrm{Pb}, \mathrm{Zn} \text { dan } \mathrm{Co}}$

\begin{tabular}{cccccccc} 
& & Jenis & \multirow{5}{*}{$\begin{array}{c}\text { Kadar } \\
\text { Nwal } \\
\text { Logam }\end{array}$} & \multicolumn{5}{c}{$\begin{array}{c}\text { Kadar Logam Berat (mg/l) } \\
\text { Berdasarkan Waktu Penyaringan }\end{array}$} \\
\cline { 3 - 7 } & & & $\mathbf{5}$ Menit & $\mathbf{1 0}$ Menit & $\mathbf{1 5}$ Menit & $\mathbf{2 0}$ Menit & 25 Menit \\
\hline 1 & $\mathrm{~Pb}$ & 0,8385 & 0,5897 & 0,4615 & 0,2128 & 0,1128 & $0,0333^{*}$ \\
2 & $\mathrm{Zn}$ & 0,4581 & 0,3089 & 0,2356 & 0,1806 & 0,1283 & 0,0785 \\
3 & $\mathrm{Co}$ & $0,0741^{*}$ & $0,0489^{*}$ & $0,0426^{*}$ & $0,0339^{*}$ & $0,0284^{*}$ & $0,0181^{*}$ \\
\hline
\end{tabular}

Keterangan :

* Memenuhi batas baku maksimun yang ditetapkan oleh pemerintah.

$\underline{\text { Tabel 2. Hasil Uji Penurunan Logam } \mathrm{Pb}, \mathrm{Zn} \text { dan } \mathrm{Co}}$

\begin{tabular}{|c|c|c|c|c|c|c|}
\hline \multirow{2}{*}{ No } & \multirow{2}{*}{$\begin{array}{l}\text { Jenis } \\
\text { Logam }\end{array}$} & \multirow{2}{*}{$\begin{array}{l}\text { Kadar } \\
\text { Awal } \\
(\mathbf{m g} / \mathbf{l})\end{array}$} & \multirow{2}{*}{$\begin{array}{c}\text { Kadar Logam Berat } \\
(\mathbf{m g} / \mathbf{l}) \text { tanpa lilitan } \\
\text { kawat }\end{array}$} & \multicolumn{3}{|c|}{$\begin{array}{c}\text { Kadar Logam Berat (mg/l) dengan Variasi } \\
\text { Jumlah Lilitan Kawat }\end{array}$} \\
\hline & & & & 1300 lilitan & 1600 lilitan & 2000 lilitan \\
\hline 1 & $\mathrm{~Pb}$ & 0,8385 & 0,3923 & $0,2128^{*}$ & 0,0051 & 0,0026 \\
\hline 2 & $\mathrm{Zn}$ & 0,4581 & 0,2147 & $0,1806^{*}$ & 0,0288 & 0,0131 \\
\hline 3 & $\mathrm{Co}$ & 0,0741 & 0,0394 & 0,0339 & 0,0079 & 0,0063 \\
\hline
\end{tabular}




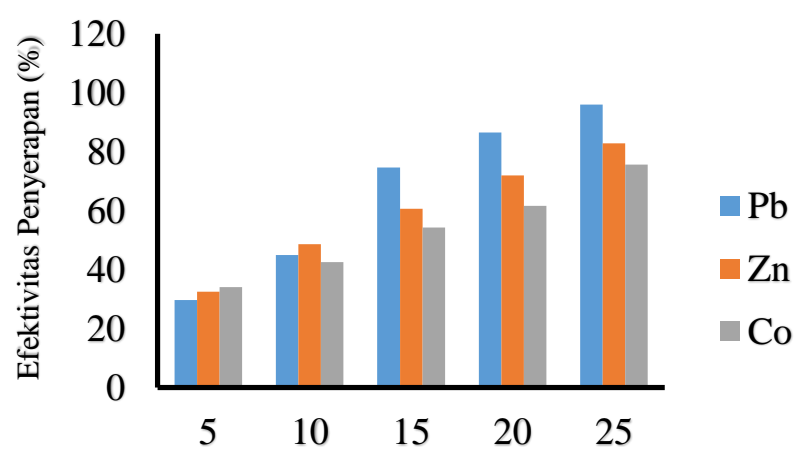

Lama Waktu Penyaringan

Gambar 1. Efek variasi lama waktu penyaringan terhadap efektivitas penyerapan logam $\mathrm{Pb}, \mathrm{Zn}$ dan $\mathrm{Co}$.

Dari Gambar 1 dapat dilihat bahwa kemampuan filter dalam menyerap logam berat $\mathrm{Pb}$ mencapai $92,95 \%$ di menit 25 sedangkan $\mathrm{Zn}$ sebesar $82,86 \%$ dan Co sebesar 75,57\%, sehingga dapat dikatakan bahwa kemampuan alat menyerap logam berat lebih efektif pada waktu penyaringan 25 menit.

\subsection{Efek variasi jumlah lilitan kawat terhadap efesiensi penyerapan pada logam $\mathrm{Pb}, \mathrm{Zn}$ dan $\mathrm{Co}$ dengan menggunakan sistem filter elektromagnetik}

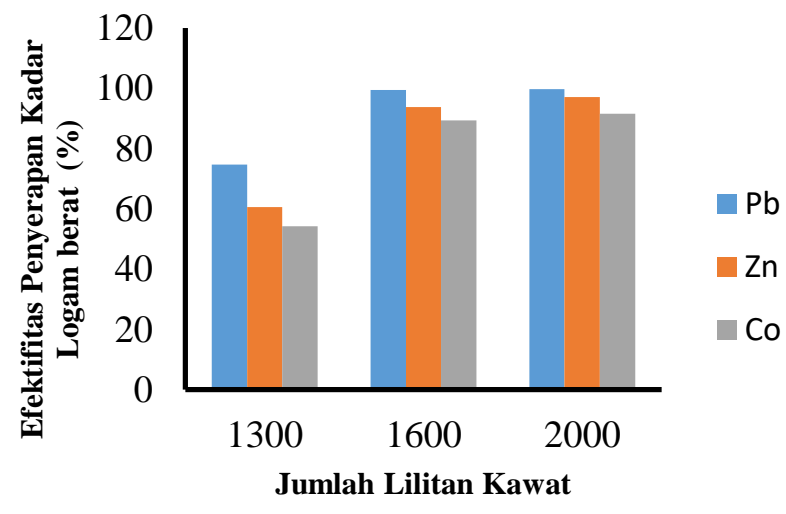

Gambar 2. Efek variasi jumlah lilitan kawat terhadap efektivitas penyerapan logam $\mathrm{Pb}, \mathrm{Zn}$ dan $\mathrm{Co}$.

Dari Gambar 2 diatas nampak bahwa serapan logam berat optimum mulai pada jumlah lilitan 1600 sampai 2000 lilitan. Hal ini memudahkan penggunaan filter ini dengan lama penyaringan hanya 15 menit maka ketiga logam berat tersebut hampir $100 \%$ terserap.

Penelitian ini menggunakan sistem penyaring air berbasis elektromagnetik dengan menggunakan ekkstrak pasir besi sebagai sebagai filler. Pasir besi merupakan bahan ferromagnetik, sehingga dapat memberikan gaya magnet pada benda yang berada di sekitarnya termaksud menarik logam berat yang terlarut pada limbah cair yang melaluinya sekaligus mengurangi warna dan bau dari air yang tercemar [12]. Dari pengujian awal sebelum menggunakan filter elektromagnetik, air laut Teluk Kendari sudah tercemar logam berat dengan kadar jauh diatas ambang batas yang ditetapkan pemerintah. Sistem filter elektromagnetik menggunakan arus listrik yang dihubungkan ke kawat yang dililit pada pipa, sehingga akan meningkatkan kuat medan magnet di dalam pipa solenoid [13], sesuai dengan Hukum Ampere bahwa medan magnet berbanding lurus dengan kuat arus listrik. Solenoida yang telah diisi dengan pasir besi, kuat medan magnetnya menjadi lebih besar jika dibandingkan dengan solenoida yang tidak diisi pasir besi. Hal ini disebabkan karena pasir besi yang berada dalam tabung solenoida telah termagnetisasi. Sistem filter elektromagnetik mampu menurunkan kelarutan suatu logam berat, dimana pada sistem filter elektromagnetik terdapat hubungan kuat medan solenoida dengan peningkatan kuat arus pada solenoida sebelum dan sesudah diisi pasir besi.

Kemampuan filter dari pasir besi menyerap logam berat yang terdapat pada air karena pasir besi didominasi oleh magnetit $\left(\mathrm{Fe}_{3} \mathrm{O}_{4}\right)$ yang berfungsi sebagai absorben untuk mengadasorpsi logam berat. Hal ini menunjukkan bahwa nanopartikel magnetik $\mathrm{Fe}_{3} \mathrm{O}_{4}$ dapat mengadsorpsi logam berat seperti $\mathrm{Pb}, \mathrm{Cu}, \mathrm{Zn}$ dan $\mathrm{Mn}$ pada variasi $\mathrm{pH}$, temperatur dan waktu kontak yang berebeda [14]. Selain itu, Sartika, dkk (2019) melakukan analisis distribusi nanopartikel $\mathrm{Fe}_{3} \mathrm{O}_{4}$ terhadap penyerapan logam berat $\mathrm{Pb}$ menunjukan produk sintesis $\mathrm{Fe}_{3} \mathrm{O}_{4}$ mampu menyerap logam $\mathrm{Pb}$ dengan baik, dan yang mempengaruhi penyerapan logam $\mathrm{Pb}$ yaitu variasi absorbennya [15]. Semakin besar absorben maka penyerapan logam $\mathrm{Pb}$ juga semakin besar menunjukan bahwa penyerapan logam $\mathrm{Pb}$ menggunakan nanomaterial pasir besi dengan variasi waktu dan hasilnya signifikan [16].

Grafik pada Gambar 1 dan Gambar 2 menunjukkan optimasi kerja filter elektomagnetik pada lama penyiraman 25 menit dan jumlah lilitan mulai dari 1600 lilitan hingga 2000 lilitan. Efektifitas penyerapan logam $\mathrm{Pb}, \mathrm{Zn}$ dan $\mathrm{Co}$ dengan sistem filter elektromagnetik dan menggunakan pasir besi sebagai fillernya menunjukan bahwa, keefektivan penyerapan logam $\mathrm{Pb}$ terjadi pada menit ke 25 dengan efektivitas mencapai 96,02\%, Zn sebesar 82,86\% dan Co sebesar 75,57\% sedangkan keefektivan berdasarkan jumlah lilitan kawat terjadi pada 2000 lilitan dengan efektivitas 99,68\% untuk $\mathrm{Pb}$, $97,14 \%$ untuk Zn dan 91,49\% untuk Co. Sementara pada menit ke 5, menunjukan bahwa efektivitas penyerapan logam Co lebih tinggi dibanding dengan $\mathrm{Pb}$ dan $\mathrm{Zn}$. Hal ini dikarenakan logam Co lebih cepat ditarik oleh pasir besi yang bersifat Feromagnetik karena mengandung $\mathrm{Fe}_{3} \mathrm{O}_{4}$. Namun pada menit ke 10 sampai 25 terjadi penurunan dalam penyerapan logam Co. Hal ini disebabkan karena penyaring yang sudah cukup panas sehingga membuat pasir besi menjadi cepat jenuh. Penyerpan logam berat tidak hanya dipengaruhi oleh kandungan magnetik pada filter akan tetap juga dapat dipengaruhi oleh pori-pori pasir sangat mendukung pemanfaatannya sebagai adsorben. Semakin kecil ukuran poripori silika maka semakin besar kemampuan absorpsinya.

\section{KESIMPULAN}

Berdasarkan hasil penelitian dan pembahasan dapat disimpulkan bahwa optimasi lama waktu penyaringan pada sisten filter elektromagnetik dengan jumlah lilitan 1300 lilitan adalah 25 menit dengan efektivitas penyerapan kadar logam $\mathrm{Pb}$ sebesar 92,95\%, Zn sebesar 82,86\% dan Co sebesar $75,57 \%$. Sitem filter elektromagnetik lebih efisien dalam menyerap logam $\mathrm{Pb}, \mathrm{Zn}$ dan Co pada jumlah lilitan 1600 dan 2000 lilitan dengan waktu penyiraman selama 15 menit. Hal ini selain mengefisienkan waktu juga alat ini dapat menyerap hampir $100 \%$ semua unsur logam berat dengan jumlah lilitan 1600 dan 2000 lilitan. Dengan demikian optimasi kerja dan 
efisiensi alat filter elektromagnetik ini pada jumlah lilitan 1600 dengan waktu penyaringan 15 menit atau menggunakan 1300 lilitan namun lama penyaringan 25 menit.

\section{DAFTAR PUSTAKA}

[1] Dahuri, R. 1998, Pengaruh Pencemaran Limbah Industri Terhadap Potensi Sumber Daya Laut. Makalah pada seminar Teknologi Pengelolaan.

[2] Ashraf, 2016, Level of selected Hary Metals in Tuna the Arabian journal for science and engineering, vol 31, No 3.

[3] Setyowati, Emerita, 2008, Studi Fisis Pengaruh Kuat Arus, Jenis Polutan Logam dan Waktu Pengambilan Output Penyaringan terhadap Efektivitas Penyaring Elektromagnetik, Jurusan Fisika FMIPA UGM, Yogyakarta

[4] Amriani, Hedarto, B, 2011, Bioakumulasi Logam Berat (Pb) Dan Seng (Zn) Pada Kerang Darah (Anadara Granosa L.), Jurnal Ilmu Lingkungan.

[5] Sofyan, M. 2017, Efek Variasi Temperatur Aktivasi Arang Aktif Kayu Mahoni (Swietenia mahagoni) terhadap Daya Serap Logam Timbal $(\mathrm{Pb})$ Dan Logam Seng ( $\mathrm{Zn})$ dari Perairan Teluk Kendari, Universitas Halu Oleo.

[6] Purnomo, Dony., 2009, Logam Berat Sebagai Penyumbang Pencemaran Air Laut, UNS, Solo

[7] Jalil, Z., Sari, E. N., Ismail, \& Handoko, E. 2014. Studi Komposisi Fasa dan Sifat Kemagnetan Pasir Besi Pesisir Pantai Aceh yang Diseparasi dengan Metode Mechanical Milling, Indonesian Journal of Applied Physics, 4(1), pp. 110-114.

[8] Yulianto A., Bijaksana S., Loeksmanto W., 2003, Comparative Study on Magnetic Characterization of Iron Sand from Several Locations in Central Java, Kontribusi Fisika Indonesia, Vol. 14 No.2
[9] Zhang Y, Xu Q, Zhang S, Liu J, Xu H, and Li J, (2013), Preparation Of Thiol-Modified $\mathrm{Fe}_{3} \mathrm{O}_{4}$ and $\mathrm{SiO}_{2}$ Nanoparticles and Their Application for Gold Recovery from Dilute Solution., Sep. Purif. Technol., 116, 391-97.

[10] Huang, Z.G., Guo, Z.P., Calka, A., Wexler, D., Lukey, C. dan Liu, H.K. 2006. Effects of Iron Oxide (Fe2O3, Fe3O4) on Hydrogen Storage Properties of Mg-Based Composites. Journal of Alloys and Compounds, Vol. 422, Hal. 299-304.

[11] KMNLH, 2004. Pedoman Penetapan Baku Mutu Lingkungan. Kantor Menteri Negara Kependudukan Lingkungan Hidup 2004. Keputusan Menteri Negara Kependudukan dan Lingkungan Hidup. Kep-51/MNLH/ 2004. Sekretariat Negara, Jakarta. 5 hal.

[12] Widianto E, Kardiman, Fauji N, Karakterisasi Pasir Besi Alam Pantai Samudera Baru dan Pemanfaatanya sebagai Filter pada Sistem Penyaring Elektromagnetik, Jurnal Riset Sains dan Teknologi, Vol 2, No 1

[13] Zulkifli, 2019, Rancang Bangun pembangkit Listrik Menggunakan Selenoida dengan pemanfaatan Fluks Magnet, Jurnal Teknik Elektro, vol 2, No 1.

[14] Damayanti, D.E., 2009, Studi Penurunan Kadar Logam Besi (Fe) dan Logam Mangan (Mn) pada Air Sumur dari Daerah Klaten dengan Penyaring Elektromagnetik, Jurusan Fisika FMIPA UGM, Yogyakarta

[15] Sartika D, dkk 2019, Studi Penyerapan Logam Berat $\mathrm{Pb}$ Menggunakan Nanopartikel Fe3O4 JPSE ,Journal of Physical Science and Engineering), Vol. 4, No. 1, 2019, Page $18-22$

[16] M. Kumari, J. C. U. Pittman, and M. Dinesh, Heavy Metals [Chromium (VI) and Lead (II)] Removal from Water Using Mesoporous Magnetite (Fe3O4) Nanospheres, Jurnal of Colloid and Interface Sci., vol. 442, pp. 120-132,2015. 